\title{
MONITORING THROUGH COMMUNITY SCIENCE: ANNA'S HUMMINGBIRD WINTER RANGE EXPANSION INTO IDAHO
}

\author{
JESSICA J. POLLOCK, HEIDI WARE CARLISLE, and HEATHER M. HAYES, \\ Intermountain Bird Observatory, Boise State University, Boise, Idaho 83725-1515; \\ jessicapollock@boisestate.edu
}

BRYCE W. ROBINSON, Ornithologi, P.O. Box 6423, Boise, Idaho 83707

\begin{abstract}
Increased urbanization and supplementary feeding are implicated in driving the expansion of the range of the Anna's Hummingbird (Calypte anna). In many areas this range expansion has been well described, but the recent expansion of the northeastern limit of the nonbreeding distribution, in winter in Idaho, has not yet been summarized. Using data from the Idaho Bird Records Committee database and www.eBird.org from 1976 through 2020, we collated records for Idaho and supplemented them with data from a community-science program of monitoring by homeowners. Our additional effort to solicit records from the community shows that database records and feeder observations alone underestimate the number of individuals present in the state. Through banding and color-marking of 58 individual hummingbirds at private residences, we documented six instances of Anna's Hummingbirds returning to a site in successive winters, found a roughly even sex ratio, and found a ratio of adults to juveniles of about 3:1. Anna's Hummingbird may now be a sparse year-round resident in parts of Idaho.
\end{abstract}

The range of Anna's Hummingbird (Calypte anna) spans the west coast of North America from Baja California to British Columbia, into inland areas of California, Arizona, New Mexico, Oregon, and Washington (Clark and Russell 2012). This distribution is a result of an 80-year history of range expansion in the West that has been described through broad-scale analysis and modeling of data from the core of the range (e.g., Clark and Russell 2012, Greig et al. 2017, Battey 2019). While climate change can contribute to widespread distributional shifts for some species (e.g., La Sorte and Thompson 2007, Coristine and Kerr 2015, Prince and Zuckerberg 2015), modeling suggests that for the Anna's Hummingbird, urbanization, landscaping with non-native plants, and supplementary feeding are extending the species' realized niche into otherwise unsuitable locations, particularly areas with colder and harsher climates (Greig et al. 2017, Battey 2019). Although these studies describe the extent and potential mechanisms involved in the species' continuing range expansion, they do not capture a recent eastward expansion of the regular winter distribution of the species into Idaho.

Here, we update the status of the Anna's Hummingbird in Idaho on the basis of records maintained by the Idaho Bird Records Committee (https://ibrc.idahobirds.net), www.eBird.org, and a community-science program of reporting by homeowners. Apart from updating the species' status in Idaho, our objectives are to characterize the trend of increasing numbers wintering from October through February since 1976 and to provide additional insights through the homeowner-sighting program and a banding and color-marking study. We document the first six confirmations of winter site fidelity in Idaho, present age and sex ratios of the overwintering population, 
and demonstrate that traditional reporting methods can underestimate true abundances.

\section{METHODS}

\section{Collating Records}

We summarized Anna's Hummingbird records in Idaho since 1976 from two sources, existing databases and solicited observations.

Database records. We extracted reports of Anna's Hummingbirds since 1976 from the database of the Idaho Bird Records Committee. Since 1 March 2011, the IBRC has stopped requesting winter records for the western and northern parts of the state; however, it still requests winter records for central and eastern areas, and also requests summer records for any part of Idaho (https://ibrc.idahobirds.net, S. Sturts pers. comm.). We also compiled sightings from www.eBird.org for October-February, 1976-2020. The IBRC defines "winter records" as those falling between 1 December and 29 February. In our study, wintering hummingbirds often appeared in October and disappeared in February, so we also included October and November records. On the basis of our unpublished data of intra-annual movements of color-marked birds, we applied two main criteria to estimate the number of individuals and avoid double-counting. If observations were more than $1 \mathrm{~km}$ apart or more than 30 days apart, we inferred they represented different individuals, and to maintain consistency in protocol and avoid detection biases, we excluded all eBird records that resulted from our banding efforts or had been entered by homeowners associated with the solicited records. We searched Christmas Bird Count data for the same years, but found the records were already represented in the other databases we explored, particularly that of the IBRC.

Solicited records. From 2015 to 2020 we actively solicited information from the local communities to understand whether Anna's Hummingbird numbers were under-reported in the existing sources. Using newsletters and posters, we worked with local groups in southwestern Idaho, including the Golden Eagle Audubon Society, the Southwestern Idaho Birders Association, and local bird seed or garden stores, to request reports of sightings. We used email-based birding listservs, the neighborhood social medium "Nextdoor," the Intermountain Bird Observatory's webpage, and statewide birding groups on other social media to solicit reports from the rest of the state.

\section{Banding}

Our efforts at banding and color-marking took place largely in Boise, opportunistically at other locations across Idaho (Table 1). After our call for sightings, we responded to homeowners' reports of hummingbirds visiting regularly from October to February and requested permission to band and color-mark them whenever possible. With homeowners' consent, we captured hummingbirds in a Hall trap (see NABC 2019) and banded and uniquely color-marked each individual. For each banded individual we recorded its age and sex, as well as morphometric data. Using correction fluid, we applied a small white mark to the forehead of each banded bird to enable easy tracking, 
TABLE 1 Anna’s Hummingbirds Banded in Idaho, 2015-2020

\begin{tabular}{|c|c|c|c|c|c|c|}
\hline Nearest city & Date banded & Age & Sex & Band number & Fat score ${ }^{a}$ & Weight (g) \\
\hline American Falls & 7 Nov 2015 & Juvenile & Male & K31201 & 3 & 5.8 \\
\hline American Falls & 17 Nov 2015 & Unknown & Female & K31202 & 2 & 5.6 \\
\hline Boise & 5 Nov 2015 & Juvenile & Male & J79768 & 1 & 4.5 \\
\hline Boise & 6 Nov 2015 & Adult & Female & L93995 & 1 & 4.1 \\
\hline Boise & 15 Nov 2015 & Adult & Male & J82384 & 1 & 5.1 \\
\hline Boise & 16 Nov 2015 & Adult & Male & J82385 & 1 & 4.5 \\
\hline Boise & 16 Nov 2015 & Adult & Female & P40595 & 1 & 4.3 \\
\hline Boise & 24 Nov 2015 & Adult & Male & J82386 & 2 & 5.8 \\
\hline Boise & 17 Dec 2015 & Adult & Female & J81972 & 2 & 4.8 \\
\hline Boise & 13 Jan 2016 & Adult & Female & J81973 & 2 & 4.5 \\
\hline Boise & 4 Nov 2016 & Juvenile & Female & K31205 & 0 & 4.4 \\
\hline Boise & 21 Nov 2016 & Adult & Female & K46514 & 1 & 4 \\
\hline Boise & 21 Nov 2016 & Adult & Male & K46924 & 2 & 5.2 \\
\hline Boise & 21 Nov 2016 & Juvenile & Male & K46925 & 1 & 4.3 \\
\hline Boise & 21 Nov 2016 & Adult & Female & K46926 & 1 & 4.3 \\
\hline Boise & 21 Nov 2016 & Adult & Female & K46927 & 2 & 4.3 \\
\hline Boise & 21 Nov 2016 & Adult & Male & K46928 & 3 & 5.6 \\
\hline Boise & 21 Nov 2016 & Adult & Female & K47085 & 2 & 4.9 \\
\hline Boise & 1 Dec 2016 & Adult & Male & K46929 & 2 & 4.9 \\
\hline Boise & 2 Dec 2016 & Juvenile & Female & K46515 & 2 & 4.2 \\
\hline Boise & 3 Dec 2016 & Juvenile & Female & K46930 & 2 & 4.6 \\
\hline Boise & 16 Oct 2017 & Juvenile & Male & $\mathrm{K} 81550^{b}$ & 1 & 4.8 \\
\hline Boise & 16 Oct 2017 & Adult & Female & $\mathrm{K} 81683^{c}$ & 1 & 4.1 \\
\hline Boise & 23 Oct 2017 & Juvenile & Female & K81551 & 1 & 4.4 \\
\hline Boise & 23 Oct 2017 & Adult & Female & K81684 & 2 & 4.8 \\
\hline Boise & 25 Oct 2017 & Adult & Female & K81685 & $\mathrm{T}$ & 4.2 \\
\hline Boise & 31 Oct 2017 & Adult & Male & $\mathrm{K} 81552^{d}$ & 1 & 4.6 \\
\hline Boise & 31 Oct 2017 & Juvenile & Female & K81553 & $\mathrm{T}$ & 4.1 \\
\hline Boise & 9 Nov 2017 & Juvenile & Female & K81554 & 3 & 5.3 \\
\hline
\end{tabular}

as these marks are highly visible even from a distance. In addition, we applied a unique color combination of nontoxic permanent ink on the breast of each bird so that individuals could be distinguished (until their next molt). We relied on homeowners' continued monitoring and reports of color-marked birds to determine whether banding in a given area was complete. If new unmarked birds appeared, we returned to band until all individuals at that home had been banded.

For each location, when possible, we recorded homeowner-estimated arrival and departure dates to make a conservative estimate of the minimum number of individuals present.

\section{RESULTS}

\section{Database Records}

The first Anna's Hummingbird documented in Idaho was in Lewiston, Nez Perce County, 20 November-17 December 1976 (Rogers 1977). Over 
TABLE 1 (continued).

\begin{tabular}{|c|c|c|c|c|c|c|}
\hline Nearest city & Date banded & Age & Sex & Band number & Fat score ${ }^{a}$ & Weight (g) \\
\hline Boise & 16 Nov 2017 & Adult & Male & K81555 & 2 & 5.1 \\
\hline Boise & 7 Nov 2018 & Adult & Male & K47030 & 1 & 4.6 \\
\hline Boise & 7 Nov 2018 & Adult & Male & K47031 & 3 & 5.8 \\
\hline Boise & 7 Nov 2018 & Adult & Male & K47032 & $\mathrm{T}$ & 4.4 \\
\hline Boise & 7 Nov 2018 & Adult & Male & K47033 & $\mathrm{T}$ & 4.2 \\
\hline Boise & 8 Nov 2018 & Adult & Female & M07786 & $\mathrm{T}$ & 4.2 \\
\hline Boise & 18 Nov 2018 & Juvenile & Male & K47035 & 1 & 4.5 \\
\hline Boise & 18 Nov 2018 & Adult & Male & K47036 & 1 & 5 \\
\hline Boise & 18 Nov 2018 & Adult & Male & K81612 & 1 & 5.2 \\
\hline Boise & 18 Nov 2018 & Adult & Male & K81613 & 3 & 5.9 \\
\hline Boise & 29 Nov 2018 & Adult & Male & K81614 & 1 & 5.1 \\
\hline Boise & 30 Nov 2018 & Juvenile & Male & K81615 & 1 & 5.1 \\
\hline Boise & $25 \operatorname{Jan} 2019$ & Adult & Female & M07787 & 1 & 3.8 \\
\hline Boise & 7 Jan 2020 & Juvenile & Male & M07760 & 1 & 4.6 \\
\hline Boise & 9 Jan 2020 & Adult & Female & M07834 & 2 & 4.5 \\
\hline Boise & $31 \operatorname{Jan} 2020$ & Adult & Male & M07761 & 1 & 4.6 \\
\hline Boise & 1 Feb 2020 & Adult & Female & M07835 & 1 & - \\
\hline Boise & 2 Feb 2020 & Adult & Female & M07836 & 2 & 5.2 \\
\hline Boise & $18 \mathrm{Dec} 2020$ & Adult & Male & M07758 & 2 & 5.4 \\
\hline Boise & 18 Dec 2020 & Adult & Female & M07833 & 1 & 4.8 \\
\hline Caldwell & 17 Nov 2016 & Adult & Male & K46923 & 3 & 5.6 \\
\hline Fruitvale & 23 Dec 2020 & Adult & Female & M07759 & 1 & 4.9 \\
\hline Hailey & 1 Nov 2019 & Adult & Female & M07790 & 1 & - \\
\hline Hayden & $15 \operatorname{Jan} 2016$ & Adult & Male & K31204 & - & - \\
\hline Hayden & 27 Dec 2018 & Adult & Female & K31931 & 3 & 5.1 \\
\hline Heyburn & 22 Nov 2015 & Juvenile & Male & K31203 & 1 & 5.1 \\
\hline Inkom & 11 Oct 2017 & Juvenile & Female & K95455 & 2 & 4.6 \\
\hline New Meadows & 10 Nov 2018 & Adult & Male & K47034 & 3 & 5.3 \\
\hline Twin Falls & 29 Nov 2015 & Adult & Male & J98802 & 3 & 5 \\
\hline
\end{tabular}

${ }^{a} \mathrm{~T}$, trace; 1 , less than $1 / 3$ in interfurcular space; $2,1 / 3$ to $2 / 3$ fat in interfurcular space; 3 , interfurcular space full

${ }^{b}$ Symmetric molt in primaries, primary 9 most recently grown, rectrices all growing in concurrently.

'Symmetric molt in primaries, primary 7 most recently grown, tail finished recent molt.

${ }^{d}$ Tail in symmetric molt, rectrix 2 on both sides growing.

the next 27 years, reports of Anna's Hummingbirds ranged from zero to two individuals annually (mean 0.64; Figure 1). During the winters of 2004-2011, reports in the IBRC database increased noticeably (range 2-7 individuals annually; mean 3.4; Figure 1). Via eBird, birders reported 151 independent winter records from 1976-2020 (mean 3.4, range 0-29 annually; Figure 1). The majority of these records were near two towns at lower elevations, Boise $(832 \mathrm{~m})$ and Lewiston $(227 \mathrm{~m})$, and mostly from October to February (Figure 2). Although most frequent in late fall/winter (October-February), reports through eBird now encompass every month of the year (March-September 2006-2014, mean 2.3, range 1-7 annually; 2015-2020, mean 13.5, range 10-23 annually).

Combined data from the IBRC database and eBird illustrate a sharp 
increase since 2011 in both the spatial distribution and numbers of Anna's Hummingbirds wintering in Idaho (Figure 2). This trend is biased toward centers of human population, whereas many sparsely populated counties lack records of the species.

\section{Solicited Records}

During the winters from 2015 to 2020, homeowners reported 36-61 individuals annually, mostly in southwestern Idaho (Figures 1 and 2). Homeowners also reported Anna's Hummingbirds outside of the period of wintering (October-February), such as an adult male in Boise observed singing regularly at the same location for four consecutive springs (2016-2019), and an adult female photographed in the same neighborhood on 12 June 2020.

\section{Banding}

Since November 2015, associates of the Intermountain Bird Observatory and banding colleague Francine Rudeen have banded and color-marked 58 individual Anna's Hummingbirds across Idaho (Table 1). The majority were in the southwestern part of the state, but some were as far north as Coeur d'Alene, Kootenai County, in the panhandle and as far east as Inkom, Bannock County, in the southeast (Table 1).

Documenting individuals. Our color-banding study measurably increased the number of individuals we were able to document at a given location. Through color-marking and resighting, we identified more individuals at most banding locations than had been reported previously from observations at feeders alone. For example, over a 2.5-week span in November 2015, we identified six different individuals at one location in Boise, when the homeowner's observations alone, based on the distinct ages and sexes present, suggested only three birds (Table 1). In the most extreme example, on a single morning on 21 November 2016, at a different home in Boise, we banded and color-marked seven birds and observed two additional distinct, unmarked birds for a minimum of nine at one location, when the homeowner's observations alone suggested just two or three birds (Table 1).

Our banding data indicate that the majority of birds captured in Idaho are adults (Figure 3 ). Of the 58 individuals captured, 22 were adult males (38\%), 20 were adult females (34\%), 8 were juvenile males (14\%), and 7 were juvenile females (12\%) (Figure 3; Table 1). Following Wells et al. (1996) and Pyle (2001; see also Howell 2003), we conservatively aged one female as unknown, as its plumage and bill-corrugation characteristics conflicted.

Site fidelity. On 9 November 2018, we confirmed site fidelity of a nonbreeding Anna's Hummingbird in Idaho for the first time when we recaptured a bird where we had banded it the previous year in November 2017. In 2019, we recaptured another two individuals at the locations of their banding the previous winter. Although not examples of precise site fidelity, we also recaptured two individuals that were within $1 \mathrm{~km}$, and a third individual within $6.5 \mathrm{~km}$, of locations of their original banding (Table 2). Homeowners did not report these birds during the intervening summer. 


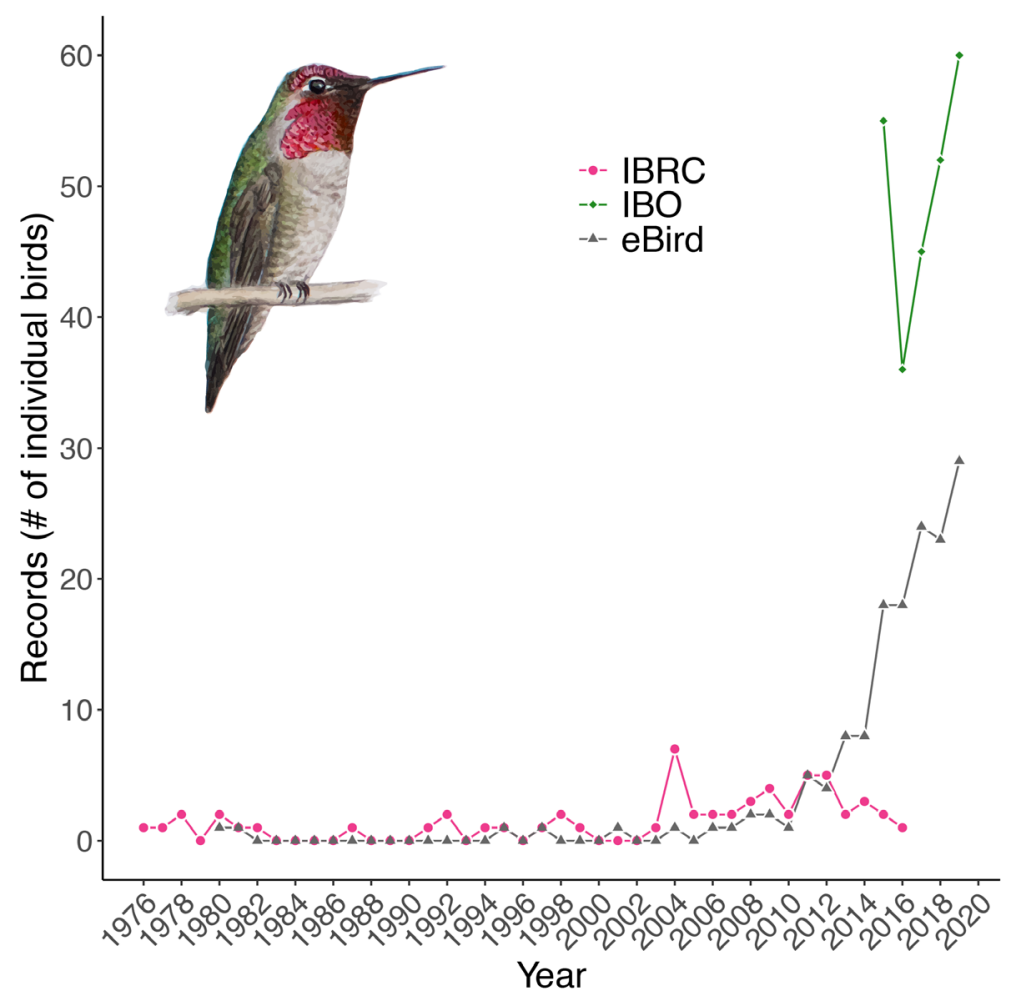

FIgURE 1. Number of reports of Anna's Hummingbird across Idaho during the nonbreeding season (October-February) by year from 1976 to 2020. Sources are records solicited by the Intermountain Bird Observatory (IBO; 2015 to 2019), the database of the Idaho Bird Records Committee (IBRC; 1976 to 2020), and www.eBird. org (1976 to 2020). Anna's Hummingbird illustration by Bryce W. Robinson.

\section{DISCUSSION}

While the expansion of Anna's Hummingbird has been modeled comprehensively for the species' core range (Greig et al. 2017, Battey 2019), these studies were based on data sources that do not represent the trend in Idaho. Our collation of records in freely accessible databases (i.e., eBird and IBRC) shows that this level of documentation adequately detected the trend of Anna's Hummingbird's occurrence increasing over time (Figure 1). However, our additional effort to solicit records from the community shows that these databases underestimated the number of individuals present in the area. The solicited homeowner reports and banding effort provided a more complete picture of the number of Anna's Hummingbirds present in Idaho during the nonbreeding season. By overlaying all sources, we updated our understanding of the magnitude of the numbers of hummingbirds wintering 
Pre 2000

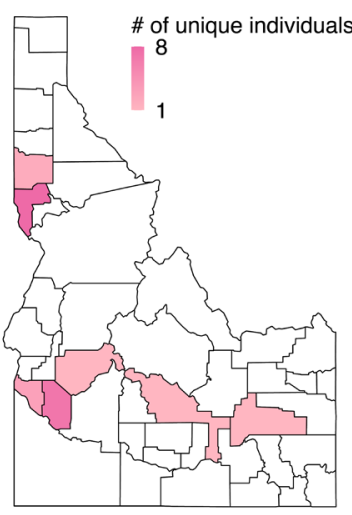

$2001-2010$

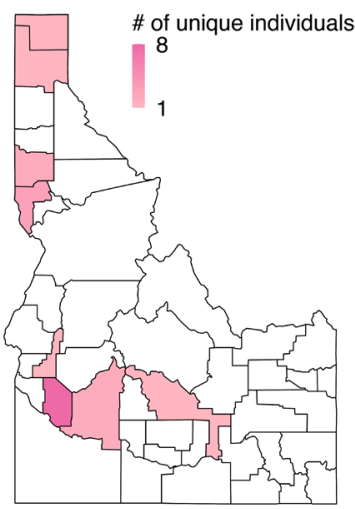

2011-2019

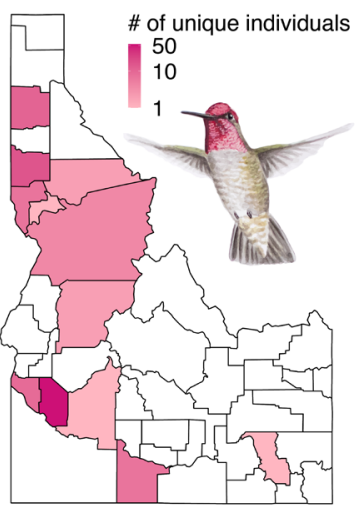

FIGURE 2. Spatial distribution by county of unique records of Anna's Hummingbird in Idaho from the Idaho Bird Records Committee (IBRC) database and www.eBird. org, by three intervals: 1976-2019 (23 individuals), 2001-2010 (19 individuals), and 2011-2019 (126 individuals). Note the scale for 2011-2019 is log transformed to facilitate interpretation relative to the previous intervals. Counties with the most Anna's Hummingbird records have relatively high human populations, whereas many counties lacking records have low human population. Anna's Hummingbird illustration by Bryce W. Robinson.

in Idaho (Figure 2), and gained fine-scale data that may clarify the patterns and processes of the range expansion.

Homeowners are an excellent resource for documenting sightings. However, there are limits to estimating the number of individuals through observations at feeders alone. Because the age and sex of many Anna's Hummingbirds other than adult males are often indistinguishable in the field, our captures allowed us to document age and sex ratios with a sample size larger than previously reported (Figure 3; Zimmerman 1973, Greig et al. 2017, Battey 2019). Future exploration of age and sex ratios on this and other frontiers

TABLE 2 Recaptures the Following Year of Anna's Hummingbirds Banded in Southwestern Idaho

\begin{tabular}{|c|c|c|c|c|}
\hline Band no. & $\begin{array}{c}\text { Date initially } \\
\text { banded }\end{array}$ & $\begin{array}{l}\text { Date(s) } \\
\text { recaptured }\end{array}$ & Distance $(\mathrm{km})^{a}$ & $\begin{array}{c}\text { Age/sex at } \\
\text { banding }\end{array}$ \\
\hline K81554 & 9 Nov 2017 & 9 Nov 2018 & $0.0(2018)$ & Juvenile female \\
\hline K81685 & 25 Oct 2017 & $\begin{array}{l}23 \text { Dec } 2019 \\
29 \text { Dec } 2018 \\
18 \text { Dec } 2019\end{array}$ & $\begin{array}{l}0.15(2019) \\
0.85(2018) \\
0.72(2019)\end{array}$ & Adult female \\
\hline K47032 & 7 Nov 2018 & 29 Nov 2019 & 1.0 & Adult male \\
\hline K47033 & 7 Nov 2018 & 29 Nov 2019 & 0.0 & Adult male \\
\hline M07787 & $25 \operatorname{Jan} 2019$ & 17 Dec 2019 & 0.0 & Adult female \\
\hline K47030 & 7 Nov 2018 & 17 Dec 2019 & 6.42 & Adult male \\
\hline
\end{tabular}

${ }^{a}$ Distance between sites of original banding and recapture the following year. 


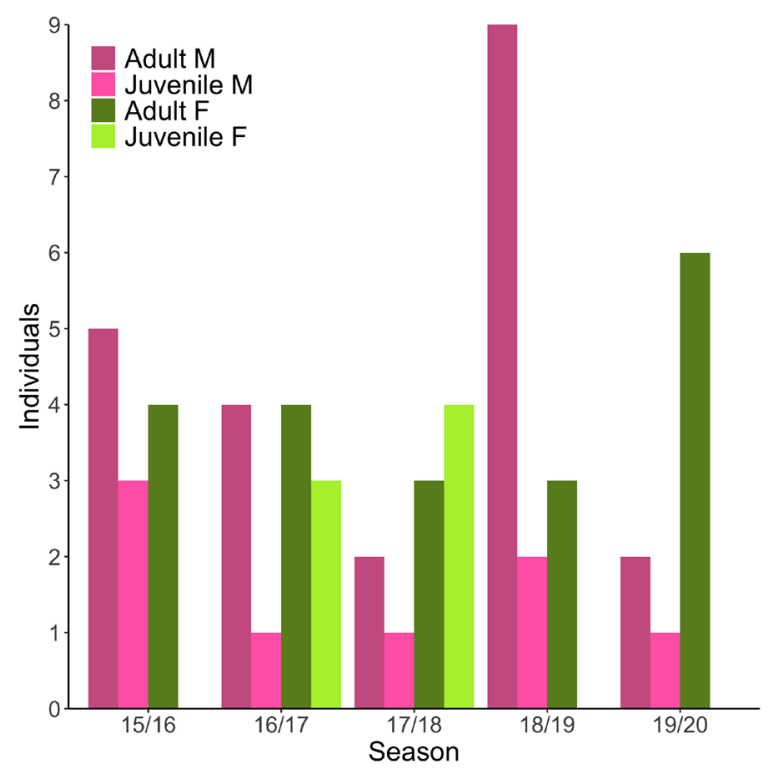

Figure 3. Age and sex ratios of 57 Anna's Hummingbirds banded in Idaho during the nonbreeding season (October-February) from 2015 to 2020. One banded female that could not be aged conclusively is omitted.

of range expansion may be informative for predicting the pace, success, and outcomes of continued colonization into new regions of expansion as they appear (Rutz 2008).

Through banding and color-marking birds, we also gained a better understanding of the overall numbers of Annas Hummingbirds in Idaho (Figure 1). Given that in other states the species' range expansion began with incidental sightings of few individuals (Clark and Russell 2012), our comparison of homeowners' counts versus numbers captured for banding implies that there may be a broad gap between apparent and actual numbers of individuals in these cases. In addition, banding allowed us to document six cases of site fidelity in successive years. These show there is some level of interannual survival, suggesting that overwintering in this region, which is much colder than the species' primary range, may not be maladaptive. Future work to more thoroughly document the duration of overwinter stays and survival of individuals will further our understanding of the severity of conditions Anna's Hummingbird can endure, as well as the mechanisms that facilitate its continuing range expansion.

The history of the expansion of Anna's Hummingbird's range shows a trend of an increase in overwintering before a breeding population is established (Zimmerman 1973, Clark and Russell 2012). Our research focused on documenting the presence of wintering individuals, which, in conjunction with an increase in the number of summer records, suggests that the Anna's Hummingbird is becoming a regular year-round resident species in Idaho. 
Although Battey (2019) did not provide data to illustrate the trend that we describe, he did illustrate (figure $3 \mathrm{~B}$ ) changes to the niche space amenable to Anna's Hummingbird to include the Snake River plain. This, coupled with increasing numbers in the last ten years, indicates that a resident population may already be present in this area of Idaho. Notably, nesting of Anna's Hummingbird was confirmed in Idaho, in Boise, for the first time in 2020 (Robinson et al. 2021). This record, along with records of putative hybrids detailed by Rudeen and Bassett (2016), and our documentation of winter site fidelity, suggests that Anna's Hummingbird may already be breeding in the region undetected at low rates, and the species may now be a sparse resident.

With the indications that a resident population of Anna's Hummingbird may be developing, or even already present at a small scale, one of the largest questions that remains regarding the winter range expansion into Idaho is where in the breeding range those colonists originated. Further study may reveal the provenance of Idaho's wintering population and provide additional clarity to the patterns and processes of this continuing range expansion.

\section{ACKNOWLEDGMENTS}

Thank you to the many homeowners who graciously invited us to band hummingbirds in their yards, and also to the 281 community scientists who contributed their observations since 2015. Thank you to Francine Rudeen and Carl Rudeen for their assistance with banding and data. Thank you to Susan Wethington and Lee Rogers for providing some bands and tools. Thanks to the Intermountain Bird Observatory's executive director and research director, Greg Kaltenecker and Jay Carlisle, respectively, for supporting this project. Thanks to Stephanie Coates for her assistance with creating initial figures, and to Robert Miller for helpful review.

\section{LITERATURE CITED}

Battey, C. J. 2019. Ecological release of the Anna's Hummingbird during a northern range expansion. Am. Nat. 194:306-315; doi.org/10.1086/704249.

Clark, C. J., and Russell, S. M. 2012. Anna's Hummingbird (Calypte anna), in The Birds of North America (A. F. Poole, ed.), no. 226, version 2. Cornell Lab Ornithol., Ithaca, NY; doi.org/10.2173/bow.annhum.01.

Coristine, L. E., and Kerr, J. T. 2015. Temperature-related geographical shifts among passerines: Contrasting processes along poleward and equatorward range margins. Ecol. Evol. 5:5162-5176; doi.org/10.1002/ece3.1683.

Greig, E. I., Wood, E. M., and Bonter, D. N. 2017. Winter range expansion of a hummingbird is associated with urbanization and supplementary feeding. Proc. Royal Soc. B: Biol. Sci. 284:20170256; doi.org/10.1098/rspb.2017.0256.

Howell, S. N. G. 2003. Hummingbirds of North America: The Photographic Guide. Princeton Univ. Press, Princeton, NJ.

La Sorte, F. A., and Thompson, F. R. III. 2007. Poleward shifts in winter ranges of North American birds. Ecology 88:1803-1812; doi.org/10.1890/06-1072.1.

North American Banding Council (NABC). 2019. The North American Banders' Manual for Hummingbirds; http://www.nabanding.net/wp-content/uploads/2019/11/Hummingbird-Manual-31_Oct_2019.pdf.

Prince, K., and Zuckerberg, B. 2015. Climate change in our backyards: The reshuffling of North America's winter bird communities. Global Change Biol. 21:572-585; doi.org/10.1111/gcb.12740. 
Pyle, P. 2001. Identification Guide to North American Birds, part 1: Columbidae to Ploceidae. Slate Creek Press. Bolinas, CA.

Robinson, B. W., Pollock, J. J., Carlisle, H. W., Hayes, H. M., and Engle, J. 2021. First documentation of successful breeding for the Anna's Hummingbird in Idaho. W. Birds 52:76-79.

Rogers, T. H. 1977. Northern Rocky Mountain-intermountain region. Am. Birds 31:352-355.

Rudeen, C., and Bassett, F. 2016. Apparent breeding by Anna’s Hummingbird in Idaho. W. Birds 47:237-241; doi.org/10.21199/WB47.3.6.

Rutz, C. 2008. The establishment of an urban bird population. J. Anim. Ecol. 77:1008-1019; doi.org/10.1111/j.1365-2656.2008.01420.x.

Wells, S., Baptista, L. F., Bailey, S. F., and Horblit, H. M. 1996. Age and sex determination in Anna's Hummingbird by means of tail pattern. W. Birds 27:204-206.

Zimmerman, D. A. 1973. Range expansion of Anna's Hummingbird. Am. Birds 27:827-835.

Accepted 16 November 2020

\section{GRANT FUNDING AVAILABLE}

Sierra Foothills Audubon grants money for bird-related science and conservation projects in the northern Sierra and the closely adjacent eastern Central Valley. For more information or to request a grant application, please contact Steve Rose (nevcountybba@gmail.com), Scientific Grants Committee chair, Sierra Foothills Audubon Society. 